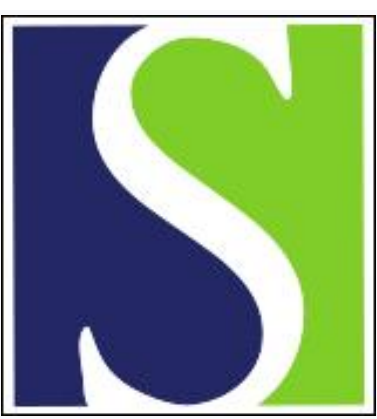

Scand J Work Environ Health 2013;39(1):27-36

https://doi.org/10.5271/sjweh.3288

Published online: 07 Mar 2012, Issue date: Jan 2013

Musculoskeletal injuries among hospital patient care staff before and after implementation of patient lift and transfer equipment

by Schoenfisch AL, Lipscomb HJ, Pompeii LA, Myers DJ, Dement JM

Affiliation: Division of Occupational and Environmental Medicine, 2200 West Main Street, Suite 400, Durham, NC 27705, USA. ashley.schoenfisch@duke.edu

The following articles refer to this text: 2014;40(1):74-81; 2019;45(6):631-641

Key terms: healthcare worker; hospital; hospital staff; intervention evaluation; lift; musculoskeletal injury; observational study; patient care; patient lift; patient lift equipment; patient transfer equipment; patient-handling injury; workers' compensation

This article in PubMed: www.ncbi.nlm.nih.gov/pubmed/22396049 


\title{
Musculoskeletal injuries among hospital patient care staff before and after implementation of patient lift and transfer equipment
}

\author{
by Ashley L Schoenfisch, PhD, ${ }^{1}$ Hester J Lipscomb, PhD, ${ }^{1}$ Lisa A Pompeii, PhD, ${ }^{2}$ Douglas J Myers, ScD, ${ }^{1}$ \\ John M Dement, $\mathrm{PhD}, \mathrm{ClH}^{1}$
}

\begin{abstract}
Schoenfisch AL, Lipscomb HJ, Pompeii LA, Myers DJ, Dement JM. Musculoskeletal injuries among hospital patient care staff before and after implementation of patient lift and transfer equipment. Scand J Work Environ Health. 2013;39(1):27-36. doi:10.5271/sjweh.3288
\end{abstract}

\begin{abstract}
Objective Using an observational research design and robust surveillance data, we evaluated rates of musculoskeletal (MS) injuries, days away from work, and restricted work days among patient care staff at a medical center and community hospital in the United States over 13 years, during which time a "minimal manual lift" policy and mechanical lift equipment were implemented.

Methods Workers' compensation claims data were linked to human resources data to define outcomes of interest and person-time at risk to calculate rates. Poisson and negative binomial regression with lagging were used to compare outcome rates in different windows of time surrounding the intervention. Patterns of MS injuries associated with patient-handling were contrasted to patterns of other MS injuries that would not be affected by the use of mechanical lift equipment.
\end{abstract}

Results At the medical center, no change in the patient-handling MS injury rate followed the intervention. A $44 \%$ decrease was observed at the community hospital. At both hospitals, the rate of days away declined immediately - before it was reasonable for the intervention to have been adopted.

Conclusions Institutional-level changes at the time of the intervention likely influenced observed results with findings only partially consistent with an intervention effect. Observational studies can be useful in assessing effectiveness of safety interventions in complex work environments. Such studies should consider the process of intervention implementation, the time needed for intervention adoption, and the dynamic nature of work environments.

Key terms healthcare worker; intervention evaluation; observational study; patient-handling injury; workers' compensation.

The risk of work-related musculoskeletal (MS) injuries is high among direct patient caregivers in the acute care hospital setting; the burden is attributed, in part, to the moving, assisting, and repositioning of patients (1-4). Such adverse conditions lead to substantial lost work time and restricted work duty $(2,5)$, and they contribute to costly workers' compensation claims (6).

A variety of patient-handling devices, including mechanical lift equipment, have been designed to reduce the physical load associated with patient care (7-14). The efficacy of mechanical lift equipment at reducing the biomechanical load of patient-handling tasks has been supported in a controlled laboratory setting
(8); however, studies offer different conclusions of the effectiveness of patient-lifting equipment (often implemented in conjunction with other intervention components) at reducing adverse MS conditions among workers in patient-care settings (15-17). A number of barriers to the use of lift equipment have been described (18-20); studies suggest mechanical patient lifts are not regularly used in patient care tasks $(1,21-25)$. Although equipment effectiveness has been demonstrated in the long-term care setting $(23,26-32)$, results may not be generalizable to the acute care setting, which is characterized by more extensive patient turnover, frequent and abrupt changes to patient acuity, a variety of patient

1 Department of Community and Family Medicine, Division of Occupational and Environmental Medicine, Duke University Medical Center, Durham, North Carolina, USA.

2 University of Texas, Division of Epidemiology, Human Genetics \& Environmental Sciences, Houston, Texas, USA.

Correspondence to: Ashley L Schoenfisch, Division of Occupational and Environmental Medicine, 2200 West Main Street, Suite 400, Durham, NC 27705, USA. [E-mail: ashley.schoenfisch@duke.edu] 
needs and demands, and various groups (eg, nursing, radiology, therapy) caring for the same patient. In any event, staff need training in equipment use and time for the equipment to be incorporated into patient care before there can be any reasonable expectation of the equipment having an effect on health and safety.

We evaluated rates of reported work-related MS injuries before and after implementation of an intervention designed to prevent patient-handling injuries among patient care staff at a large medical center and affiliated smaller community hospital in the US over a 13-year period. The intervention included patient lift and transfer equipment implemented in a staggered fashion on patient care units following a policy shift to a "minimal manual lift environment" (MMLE). This study was not designed to evaluate the efficacy of lift equipment. Rather, this analysis represents part of a comprehensive effort to evaluate effectiveness and understand adoption of lift equipment in the acute care hospital setting (20, 33-35).

\section{Methods}

Setting, intervention, and implementation

This work was conducted in a large tertiary care medical center and an affiliated community hospital within a university-based healthcare system in North Carolina, US. The implementation process has been described previously (34). Briefly, in October 2004 the medical center implemented a MMLE policy in its in-patient nursing units. The policy was adopted by the community hospital in January 2005. Lift equipment and transfer devices were introduced to in-patient units in a staggered fashion following the policy change, and a train-the-trainer approach was used to support the instruction of nursing staff in the safe use of equipment and the MMLE policy. Promotion of the policy and lift equipment occurred at both the hospital- and unit-level.

\section{Contextual considerations}

Several ancillary events were relevant to the nature and timing of this study. A major revision to the Workers' Compensation (WC) policy (effective July 2004) affected the reporting and compensation of work-related injuries and illnesses in the health system. The new policy called for the reporting of injuries and illnesses within 24 hours of the incident. Also, costs associated with lost workdays shifted from the WC office to the budget of the unit nurse manager, and efforts were made by the WC office to close injury claims and return injured workers to work more quickly. Finally, also in
2004, there was a change in occupational medicine practice at the community hospital from the communitybased employee health physician to the medical center occupational medicine program.

\section{Data sources}

Administrative data for this study came from the Duke Health and Safety Surveillance System (DHSSS) (36), which captures data from a variety of sources within the university-based healthcare system. This study used linked de-identified data from Human Resources (HR), WC, and an employer-sponsored insurance eligibility file. WC data were available from 1997-2009 at the medical center and from 2000-2009 at the community hospital, providing information on injury date, nature, agent, days away from work, restricted work days, and compensation received by the employee. WC claims were restricted to those with nature codes suggestive of a MS injury: "sprain/strain," "dislocation," "carpal tunnel," "pain/inflammation," and "twist." These MS injury claims were defined as whether they resulted from a patient-handling task(s), using injury agent codes and brief text descriptions of the incidents (3). Denied claims (those determined to be non-work-related) were not included.

HR data were used to restrict the source population to direct patient caregivers and unit managers on patient care areas of interest at the medical center and community hospital. The study population also included workers in the hospitals' internal float pools and patient transport services. These data provided employee-level demographic and work information, including age, gender, race, job title and work location (ie, unit, hospital). For each calendar year of observation, HR data also provided each worker's usual work schedule (number of hours per week) and duration of employment in the health system. These data were used to estimate full-time equivalents (FTE) per worker per year ( 1 FTE=2000 worker hours), providing a measure of time at risk for rate calculations.

\section{Data analysis}

Using FTE as the time at risk, crude incidence density rates (injuries per $100 \mathrm{FTE}$ ), incidence rate ratios (IRR) and $95 \%$ confidence intervals $(95 \% \mathrm{CI})$ were calculated for MS injuries by type (patient- versus non-patienthandling), worker characteristics and over time. A similar approach was taken to examine the total number of restricted work days and days away from work associated with claims. Restricted work days and days away from work were assigned to the calendar month in which the injury occurred, as provided in the WC claims data.

Changes in incidence density rates before and after 
the lift equipment and policy change went into place in each unit were calculated, stratified by whether the outcomes were associated with patient-handling tasks. Because the intervention was designed to prevent adverse MS conditions associated with patient-handling tasks, patterns of non-patient-handling injuries over the same time period that mirror those of the patienthandling injuries could indicate overall changes in administrative or care practices, rather than an intervention effect. Also, assuming the 2004 policy calling for injuries to be reported within 24 hours would be more likely to affect reporting of less severe injuries, we restricted some analyses to injuries that received medical care and/or resulted in days away from work.

Time at risk and the outcomes of interest were stratified by hospital, job title, gender, race, age, years of employment within the health system and presence of lift equipment (yes/no) based on the date it was introduced to the worker's work unit. Age, hospital, tenure, job title, and equipment presence were allowed to vary over time, with allocation of time at risk to the appropriate strata over the 13-year period. Poisson regression, which can incorporate both the time at risk contributed by each subject and changes in covariate values over time (37), was used to calculate injury rates, crude and adjusted IRR and 95\% CI. Because counts of restricted work days and days away from work were highly skewed and exhibited greater variability than expected for a Poisson distribution (ie, over-dispersed), negative binomial regression models were used in analyses of these data to accommodate the extra variation (38). Models also employed a scaling factor [estimated with the PSCALE option in PROC GENMOD in SAS version 9.1 (SAS Institute, Cary, NC, USA)] to control for over-dispersion (Pearson chi-square/degrees of freedom $>1.5$ ). The offset for these models was specified as the natural $\log (\ln )$ of the rate denominator (ie, FTE) in order to include a measure of time at risk that varied within strata.

In evaluating intervention effectiveness, initial multivariate models were constructed for each outcome to account for multiplicative interaction between the intervention and hospital as well as for potential confounders. Initial multivariate models included all worker and workplace variables; a backward elimination strategy was employed to arrive at a more parsimonious model. Only variables with a type $3 \mathrm{P}$-value $<0.05$ or those whose removal led to a $\geq 10 \%$ change in the estimate for at least one other predictor variable were retained.

In evaluating the effect of the lifting devices on patient-handling MS injury rates, we were interested in controlling for non-intervention related trends affecting rates of all injuries over the time period of interest. To do so, regression models of patient-handling MS injuries included the ln (number of non-patient-handling
MS injuries) as the offset. The basis of this approach is similar to the incorporation of external standard rates into a multiplicative regression model to estimate the standardized mortality ratio for one or more exposed categories relative to an unexposed category (39). In our scenario, the corresponding measure would be the standardized rate ratio. This model postulates that, in the absence of an intervention effect, the ratio of patienthandling to non-patient-handling MS injury rates should be reasonably constant over the follow-up period. We assume there are no interventions that are reducing rates of non-patient-handling injuries alone. Failure to meet this assumption could lead to more conservative (ie, closer to null) estimates of the effect of the lifting devices on patient-handling injury rates.

Lagging techniques were used to evaluate periods of time after initial intervention implementation when the intervention was most effective. These techniques were considered appropriate given that we would expect to see a gradual, rather than an immediate, effect due to the time required for staff training on the equipment and adoption of the equipment on units. Comparisons of IRR were made before and after the intervention went into effect, with lagging by six-month intervals post-intervention.

The Duke University Medical Center Institutional Review Board approved all procedures.

\section{Results}

The study cohort consisted of 11545 patient care staff who contributed 28446 FTE over the 13-year period. Most of the person-time was contributed by workers at the medical center $(83 \%)$ and females $(85 \%)$. At entry into the study cohort, workers averaged 33 (median 31 , range 17-75) years of age, and had accumulated an average of 2.4 years of employment (median 0.5, range $0-43$ years) in the healthcare system. The racial groups most represented were white $(65 \%)$ and black $(28 \%)$. In-patient nurses were the largest work group accounting for $66 \%$ of the FTE, followed by nurses' aides (15\%) and radiology staff $(12 \%)$. Patient care unit managers, patient transporters and physical and occupational therapy (PT/OT) staff each constituted $<5 \%$ of the total FTE. Exact distributions of person-time have been previously reported (33).

The 2156 MS injuries incurred among 1514 workers over the 13-year time period corresponded with an overall rate of 7.6 injuries per $100 \mathrm{FTE}(95 \% \mathrm{CI}$ 7.3-7.9). Nearly three-quarters of the MS injuries [72\% $(\mathrm{N}=1543)]$ were attributed to patient handling. Among specific work groups, the proportion of injuries attributed to patient handling was highest among PT/OT aides 
(91\%), PT/OT (87\%) and in-patient nurses' aides (78\%) and lowest among managers (31\%). The proportion of injuries attributed to patient handling decreased with increasing age, from $84 \%$ among workers $<25$ years old to $62 \%$ among workers $\geq 55$ years. Adjusting for worker and workplace characteristics, MS injury rates were higher among females compared to males. Rates of patient-handling injuries were similar across age categories and decreased with increasing tenure among those with $\geq 1$ year of work experience. Among various workgroups, patient care unit managers had the lowest rate of patient-handling MS injuries. The highest rates were seen among in-patient nurses' aides and PT/OT staff, particularly PT/OT aides. Variability by job title was not observed for non-patient-handling injuries and disorders. Patient-handling MS injury rates at the com- munity hospital were twice those seen at the medical center (adjusted IRR 1.7, 95\% CI 1.5-1.9) (table 1).

Overall declines were seen in the rate of patient-handling MS injuries at both hospitals, although rates were consistently higher at the community hospital compared to the medical center. Rates of non-patient-handling MS injuries were lower than rates of patient-handling MS injuries at both hospitals (figure 1).

The rate of days away from work associated with patient-handling MS injuries (67.5 per 100 FTE) was higher than that for days away associated with nonpatient-handling MS injuries (17.1 per 100 FTE). A similar pattern was observed for the rate of restricted work days (94.1 per 100 FTE for patient-handling MS injuries; 35.6 per 100 FTE for non-patient-handling injuries). At the medical center and community hospital,

Table 1. Incidence rates, incidence rate ratios (IRR) and 95\% confidence intervals (95\% CI) of work-related musculoskeletal injuries stratified by type and patient caregiver characteristics, workers' compensation claims data, 1997-2009, using Poisson regression models. ${ }^{a}$ [PT/OT=physical therapist/occupational therapist.]

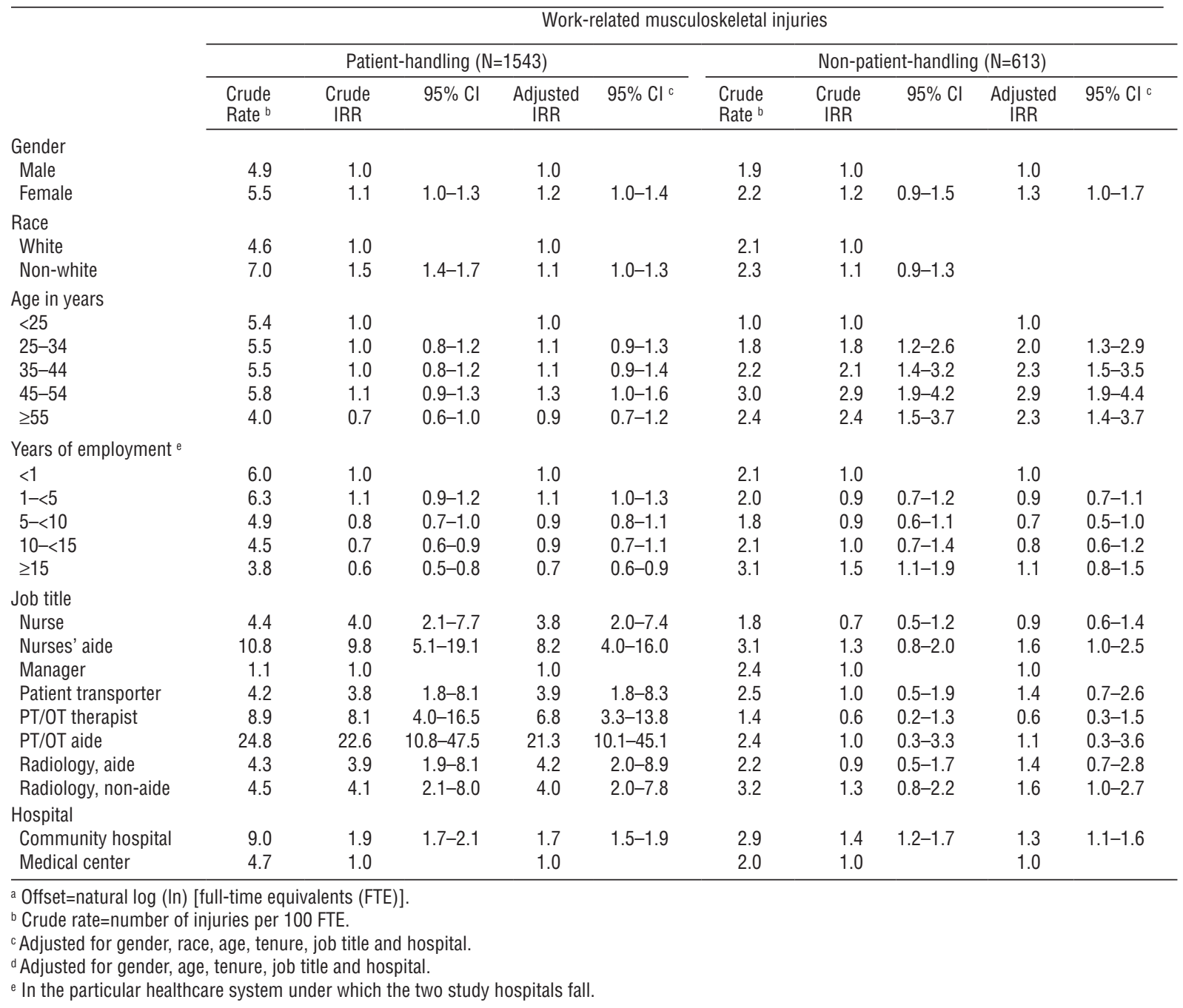




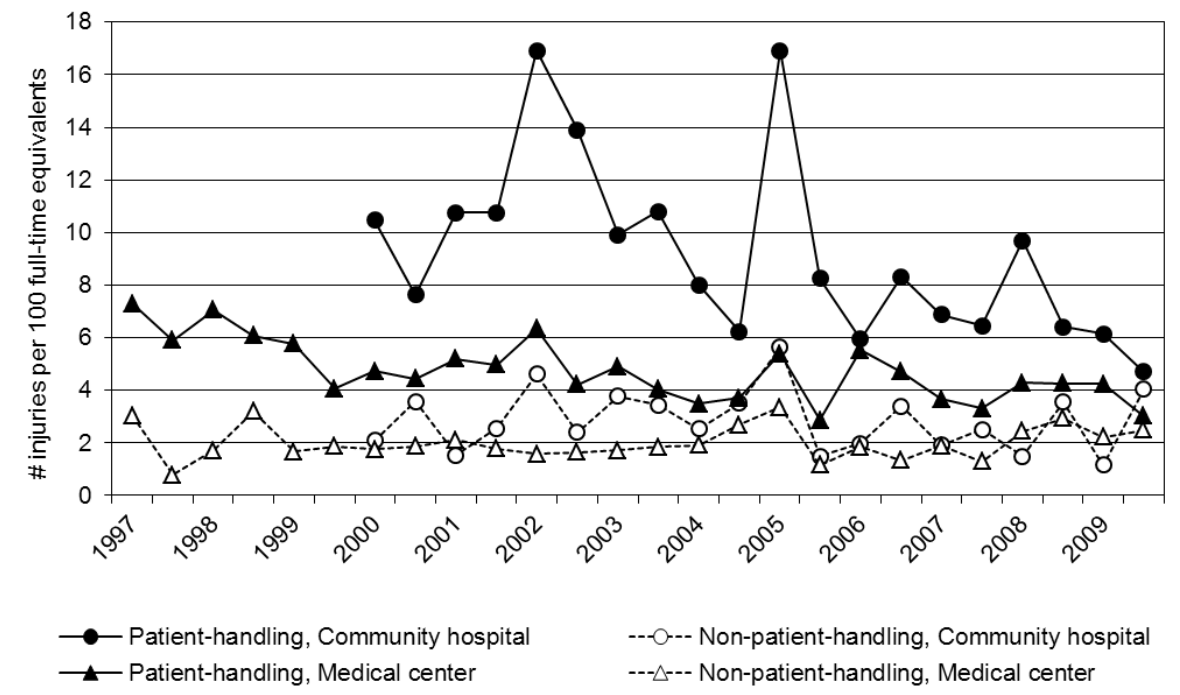

Figure 1. Crude rates of reported work-related musculoskeletal injuries over time, stratified by injury type and hospital, 1997-2009. the number of days away from work per FTE associated with a patient-handling MS injury exhibited a sharp increase from 2000 to 2002, followed by an abrupt and sharp decrease in 2003; rates of days away from work remained considerably lower for the remainder of the study period. Rates of restricted work days associated with patient-handling MS injuries declined over the time period at the medical center; contrasting patterns were seen at the community hospital where extremely low rates in earlier years were followed by a sharp increase in 2005 and considerable decrease in years following. At both hospitals, rates of days away from work and restricted work days associated with nonpatient-handling injuries were lower (but more unstable due to fewer events) than those associated with patienthandling injuries.

MS injury rate comparisons before and after implementation of the lift equipment are presented in figure 2 by hospital, with lagging at 0 (no lag), 6, 12, and 18 months after introduction of the lift equipment on the unit. At the medical center, no change in the rate of patient-handling musculoskeletal injuries was observed following the intervention with no lagging (adjusted IRR $1.01,95 \%$ CI $0.79-1.28)$. As lag time increased, the IRR suggested a protective effect of the intervention; results are statistically non-significant. At the community hospital, a significant decrease in patient-handling musculoskeletal injuries was observed following the intervention with no lagging (adjusted IRR 0.56, 95\% CI 0.36-0.87), and this protective effect became more extreme as the amount of lag time increased. When restricting to injuries which received medical care and/or resulted in days away from work, results (not shown) were nearly identical.

Pre- and post-equipment implementation analyses related to the number of days away from work and restricted work days associated with musculoskeletal injuries per FTE are presented in figure 3. Results were similar by hospital and are presented overall. Extreme declines were observed in the rates of the number of days away from work associated with patient-handling (adjusted IRR 0.10, 95\% CI 0.04-0.22) and non-patient handling (adjusted IRR 0.01, 95\% CI 0.003-0.04) injuries following the intervention with no lagging, and this effect measure was sustained as lagging windows were applied. In contrast, increases were observed in the number of restricted work days associated with patient-handling musculoskeletal injuries per FTE following implementation of the lift equipment with no lagging (adjusted IRR 2.76, 95\% CI 1.69-4.50); the change became more attenuated as the amount of lag time increased. No statistically significant change was observed in the rate of restricted work days associated with non-patient-handling musculoskeletal injuries, except with an 18-month lag window applied (adjusted IRR $0.37,95 \%$ CI $0.17-0.81$ ).

\section{Discussion}

WC claims and HR data were linked to examine rates of injury, days away from work, and restricted work days among a large cohort of patient caregivers in an acute care hospital setting surrounding the implementation of a MMLE policy and patient lift and transfer equipment. Injury patterns were examined in varied time windows and patient-handling injuries were contrasted to nonpatient-handling MS injuries that would not be affected by lift equipment. The use of an offset defined as $\ln$ (number of non-patient handling injuries) in mathemati- 

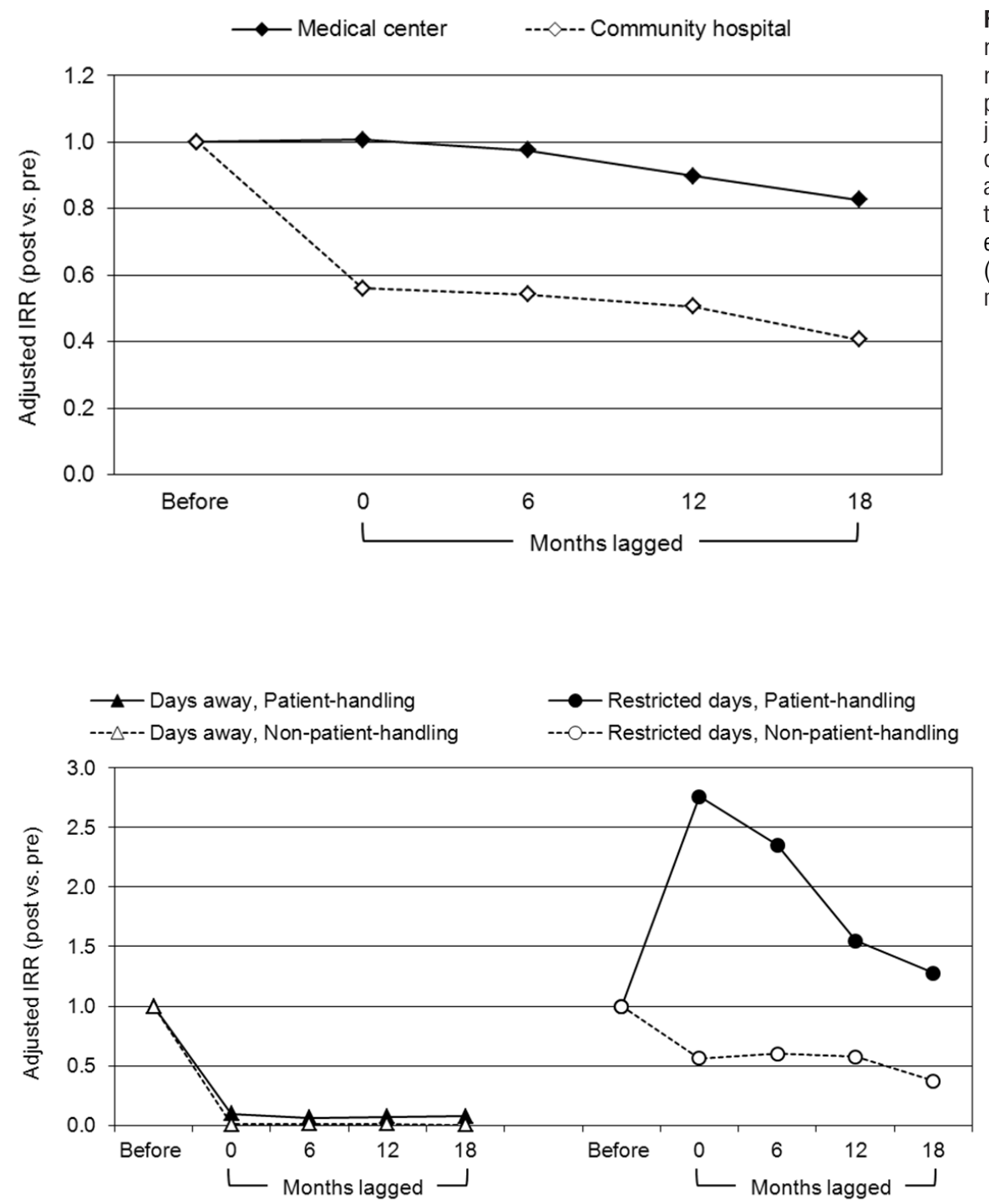

Figure 2. Adjusted (for gender, age, race, tenure, and job title) incidence rate ratios (IRR) for work-related patient-handling musculoskeletal injuries before and after the introduction of lift equipment, stratified by hospital and lagged by different amounts of time. Note: Poisson regression models employed an offset of natural log (In) (number of non-patient-handling musculoskeletal injuries).
Figure 3. Adjusted incidence rate ratios (IRR) of number of days away a and restricted work days $\mathrm{b}$ associated with work-related musculoskeletal injuries, before and after implementation of the lift equipment, stratified by injury type and lagged by different amounts of

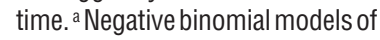
rates of days away associated with patient-handling musculoskeletal injuries were adjusted for race, age and job title; models of rates of days away associated with nonpatient-handling musculoskeletal injuries were adjusted for age and job title. ${ }^{b}$ Negative binomial models of rates of restricted days associated with each type of injury were adjusted for gender, age, tenure and job title. Note: Models employed an offset of natural log (In) (full-time equivalents). cal models permitted the direct control of trends over the time period.

At the medical center, no change in the rate of patient-handling MS injuries was observed following implementation of the lift equipment. At the community hospital, we observed a $44 \%$ decrease in the rate of patient-handling injuries following implementation of the patient lift and transfer equipment. Results were similar when restricted to more severe injuries. Differences observed by hospital may be a function, in part, of early efforts to address patient-handling concerns at the medical center in the three years prior to the intervention. Overall rates of MS injury were higher at the community hospital compared to the medical center prior to the intervention, perhaps allowing more of an effect of the intervention to be observed at the commu- nity hospital. Results were sensitive to the definition of the intervention. If the intervention was defined as the date of the policy introduction, rather than the date the equipment was placed on the unit, a $36 \%$ decrease was observed in the rate of patient-handling injuries at the medical center, and no change was observed in the rate of patient-handling injuries at the community hospital.

In line with the assumption that time is needed for staff to be trained and adopt the lift equipment, results from both hospitals suggest the intervention offered more of a protective effect as the amount of lag time increased. Adoption of the lift equipment, however, has been described as limited at these hospitals (34, 35 ), indicating that any observed decline in rates of patient-handling injuries following the intervention are likely due, at least in part, to other factors. Considering 
there are types of patient-handling activities (eg, turning patients) for which lift equipment was not available in the units and scenarios (eg, emergency situations) in which lift use was not required, it is unrealistic to assume the lift and transfer equipment could potentially prevent all MS patient-handling injuries. In a study of workers at the medical center prior to the intervention, lift equipment may have prevented $40 \%$ of the MS patient-handling injuries incurred (3). Furthermore, the acute care hospital setting is characterized by changes over time (eg, increasing levels of patient acuity and obesity, higher patient re-admittance rates, shorter lengths of stay, decreasing nurse-to-patient ratios, prolonged worker shift patterns) (40-42) which could influence the physical work demands faced by caregivers as well as the use of lifting devices in patient care.

We observed abrupt and sustained declines in days away from work associated with both patient- and non-patient-handling injuries immediately following implementation of the lift equipment at both hospitals. We expected a decrease in the rate of days away from work related to patient-handling injuries following the intervention, assuming the lift equipment reduces both the frequency of patient-handling injuries with days away, the intensity of such injuries and (perhaps) the ability of the lift equipment to facilitate return to work for injured workers. However, we expected to observe a larger effect of the intervention as the number of months lagged increased, rather than the observed immediate decline, due to the time required for staff training on the equipment and adoption of the equipment in units. The immediate and sustained effect we observed is likely attributed to administrative changes implemented at the same time as the placement of lift equipment in units, including the requirement that injuries be reported within 24 hours and the shift of the costs associated with days away from work to the budgets of the nurse managers. These new policies would have affected both patient- and non-patient-handling injuries, in line with observed trends.

We observed an increase in the rate of restricted work days associated with patient-handling injuries. Such findings may suggest that the equipment decreased injury severity, allowing a worker who would have had a day away from work to instead work on restricted work duty. Another explanation could be that the lift and transfer equipment facilitates return to work in a restricted capacity, assuming the devices lessen the physical demand of patient care tasks compared to not using the devices. Though plausible explanations of these unexpected observations, they fail to consider the context from which these data came and provide another good example of the limits of rate data alone. The shifting of costs associated with days away from work to the budgets of the nurse managers could have led more nurse managers to seek restricted work tasks for injured workers. Also, occupational medicine practice at the community hospital switched occupational medicine providers in 2004. Compared to the more recent provider, the former provider was more inclined to assign days away for occupational low back injuries, rather than prescribe restricted work duty. Furthermore, the high rates of restricted work days at the community hospital following the physician change in conjunction with considerably lower rates overall at the medical center in early years strongly influenced the results.

Our use of WC claims data in conjunction with linked information on work time at risk enhanced these analyses. However, using WC data to define the injury experience among these workers limited us to injury claims that were reported and accepted. Under-reporting of work-related MS injuries and disorders is widely recognized, and an understanding of injury reporting practices is needed when interpreting results of intervention effectiveness evaluations based on injury surveillance data $(4,43-45)$. In the hospitals we studied, underreporting of patient-handling injuries has been documented (46) and may have been influenced by the administrative change calling for reporting of an injury within 24 hours. Furthermore, among the study population, we observed a considerable difference in the number of denied MS injury claims prior to the policy change and equipment implementation (mean: 1 denied claim per year) compared to after (mean: 19 claims per year), and $84 \%$ of the denied claims were for patient-handling injuries.

Evaluations of the effectiveness of workplace interventions, such as mechanical patient lift equipment, often employ workers' compensation WC claims data to capture outcomes of interest (eg, work-related injuries, lost work days, restricted work days, claim cost). There are concerns, however, that WC claims as the only source of data on MS outcomes may lead to an underestimate of the true injury burden, due in part to the failure to recognize the influence of work-related exposures on MS conditions not arising from a defined event (47). To offset this weakness, we have also reported the evaluation of private healthcare claims for employees of the health system (48). While we observed noteworthy variations in rates of private insurance-covered healthcare use for low back and shoulder diagnoses by job title when controlling for confounding factors, we did not find evidence of a shift in work-related injuries from WC to private insurance following the administrative changes or intervention.

This study demonstrates the importance and utility of robust, longitudinal surveillance data in long-term evaluations of the effectiveness of workplace safety interventions, as well as the importance of measures of intervention adoption and contextual details in framing an analytical approach and interpreting results. Given 
the relevant institutional changes occurring over the study period, our use of an internal comparison injury group was stronger methodologically than use of an external comparison population. Patterns we observed in rates of injuries and related outcomes would have likely been missed using a simple before-and-after design or a design without an appropriate group of injuries for comparison. These issues are of particular importance given the serious limitations in the conduct of randomized controlled trials for long-term evaluation in occupational settings. The broad evaluation under which this study falls also incorporated qualitative techniques and measures of intervention fidelity $(20,34,35)$. We recognize the need for financial and time resources in order to carry out such a comprehensive observational evaluation; however, failure to thoroughly understand interventions designed to enhance occupational safety and health may lead to misguided and invalid conclusions of an intervention's effectiveness.

\section{Concluding remarks}

This observational study used administrative data from an ongoing surveillance system (36) to describe injury experiences among patient care staff at a large medical center and smaller affiliated community hospital over 13 years surrounding a policy shift and gradual introduction of patient lift and transfer equipment designed to reduce patient-handling injuries. Given the gradual nature of the intervention adoption process in the hospital setting, sufficient follow-up time is needed to detect any real intervention effect (50). Our use of existing, robust surveillance data provided the opportunity to capture a detailed picture of a large cohort of workers and its MS injury experience over a lengthy period of time, allowed for the calculation of rates, and has the potential to be updated for longer-term evaluation.

Following the introduction of the MMLE policy and implementation of patient lift and transfer equipment, we observed declines in patient-handling injuries (at the community hospital only) and days away associated with patient-handling injuries at both hospitals. However, we do not believe the observed declines are solely the result of the policy and/or lift equipment. Institutional-level changes which occurred at the time of the intervention - including a shift in the responsibility of lost work day costs from the hospital to nursing unit managers (in efforts by the WC office to achieve faster return to work of injured employees and close WC claims more quickly) and a requirement that work-related injuries be reported within 24 hours - likely played a role.

Our experiences illustrate the need to understand contextual details surrounding the way work-related injury outcome data are collected and influenced, as well as the way in which the intervention is implemented and defined; such details were paramount in interpretation of our study findings. At each hospital, the intervention included a hospital-wide policy and introduction of patient lift and transfer equipment. Although the policy took place at a single point in time, the lift equipment was phased into patient care units in a staggered fashion, and overall adoption was limited $(34,35)$. Accounting for the date the equipment was placed on the unit compared to simply assigning the intervention as present by the date of the policy shift made a difference in terms of how one would interpret the effect of the intervention.

Interventions effective at preventing patient-handling injuries in the acute care hospital setting are clearly needed. Our results suggest that studies designed and conducted to evaluate intervention effectiveness should account for the process of intervention implementation, the time needed for intervention adoption, the dynamic nature of the hospital environment, and the complex nature of the healthcare system in which injured workers are treated as we seek to understand interventions in complex occupational settings.

\section{Acknowledgements}

The US National Institute for Occupational Safety and Health (NIOSH) provided funding for this project through RO1 OH008375.

\section{References}

1. Byrns G, Reeder G, Jin G, Pachis K. Risk factors for work-related low back pain in registered nurses, and potential obstacles in using mechanical lifting devices. J Occup Environ Hygiene. 2004;1:11-21. http://dx.doi. org/10.1080/15459620490249992.

2. Pompeii LA, Lipscomb HJ, Dement JM. Surveillance of musculoskeletal injuries and disorders in a diverse cohort of workers at a tertiary care medical center. Am J Ind Med. 2008;51:344-56. http://dx.doi.org/10.1002/ajim.20572.

3. Pompeii LA, Lipscomb HJ, Schoenfisch AL, Dement JM. Musculoskeletal injuries resulting from patient handling tasks among hospital workers. Am J Ind Med. 2009;52(7):571-8. http://dx.doi.org/10.1002/ajim.20704.

4. Retsas A, Pinikahana J. Manual handling activities and injuries among nurses: an Australian hospital study. J Adv Nursing. 2000;31(4):875-3. http://dx.doi.org/10.1046/j.13652648.2000.01362.x.

5. Pompeii LA, Lipscomb HJ, Dement JM. Predictors of lost time from work among nursing personnel who sought treatment for back pain. Work. 2010;37(3):285-95.

6. Waehrer GW, Leigh JP, Miller TR. Costs of occupational injury 
and illness within the health services sector. Int J Health Serv 2005;35(2):343-59. http://dx.doi.org/10.2190/RNQ3-0C13U09M-TENP.

7. LeBon C, Forrester C. An ergonomic evaluation of a patient handling device: the elevate and transfer vehicle. Appl Ergon. 1997;28(5/6):365-74. http://dx.doi.org/10.1016/S00036870(97)00003-3.

8. Zhuang Z, Stobbe TJ, Hsiao H, Collins JW, Hobbs GR. Biomechanical evaluation of assistive devices for transferring residents. Appl Ergon. 1999;30:285-94. http://dx.doi org/10.1016/S0003-6870(98)00035-0.

9. Zhuang Z, Stobbe TJ, Collins JW, Hsiao H, Hobbs GR. Psychophysical assessment of assistive devices for transferring patients/residents. Appl Ergon. 2000;31:35-44. http://dx.doi org/10.1016/S0003-6870(99)00023-X.

10. Keir PJ, MacDonell CW. Muscle activity during patient transfers: a preliminary study on the influence of lift assists and experience. Ergon. 2004;47(3):296-306. http://dx.doi.or $\mathrm{g} / 10.1080 / 0014013032000157922$.

11. Baptiste A, Boda SV, Nelson AL, Lloyd JD, Lee WE. Frictionreducing devices for lateral patient transfers: A clinical evaluation. AAOHN J. 2006;54(4):1-8.

12. Lloyd JD, Baptiste A. Friction-reducing devices for lateral patient transfers: A biomechanical evaluation. AAOHN J. 2006;54(3):113-9.

13. Pellino T, Owen BD, Knapp L, Noack J. The evaluation of mechanical devices for lateral transfers on perceived exertion and patient comfort. Orthop Nurs. 2006;25(1):4-10. http:// dx.doi.org/10.1097/00006416-200601000-00003.

14. Rice M, Woolley S, Waters T. Comparison of required forces between floor-based and overhead-mounted patient lifting devices. Ergon. 2009;52(1):112-20. http://dx.doi. org/10.1080/00140130802481123.

15. Bos EH, Krol B, Van der Star A, Groothoff JW. The effects of occupational interventions on reduction of musculoskeletal symptoms in the nursing profession. Ergon. 2006;49(7):70623. http://dx.doi.org/10.1080/00140130600578005.

16. Dawson AP, McLennan SN, Schiller SD, Jull GA, Hodges PW, Stewart S. Interventions to prevent back pain and back injury in nurses: a systematic review. Occup Environ Med. 2007;64:642-50. http://dx.doi.org/10.1136/ oem.2006.030643.

17. Hignett S. Systematic review of patient handling activities starting in lying, sitting and standing positions. J Adv Nurs. 2003;41(6):545-52. http://dx.doi.org/10.1046/j.13652648.2003.02566.x

18. Koppelaar E, Knibbe JJ, Miedema HS, Burdorf A. Individual and organizational determinants of use of ergonomic devices in healthcare. Occup Environ Med. 2011 Sep;68(9):659-65. http://dx.doi.org/10.1136/oem.2010.0559.39.

19. Koppelaar E, Knibbe JJ, Miedema HS, Burdorf A. Determinants of implementation of primary preventive interventions on patient handling in healthcare: a systematic review. Occup Environ Med. 2009;66:353-60. http://dx.doi. org/10.1136/oem.2008.042481.
20. Myers DJ, Schoenfisch AL, Lipscomb HJ. Cultural influences on workplace safety: An example of hospital workers' adoption of patient lifting devices. Saf Sci. 2012;50:494-501. http:// dx.doi.org/10.1016/j.ssci.2011.10.015.

21. Engkvist IL. Evaluation of an intervention comprising a No Lifting Policy in Australian hospitals. Applied Ergon. 2005;37(2):141-8. http://dx.doi.org/10.1016/j. apergo.2005.05.008.

22. Engkvist IL. Back injuries among nurses - A comparison of the accident processes after a 10-year follow-up. Saf Sci 2007;46:291-301. http://dx.doi.org/10.1016/j. ssci.2007.06.001.

23. Evanoff B, Wolf L, Aton E, Canos J, Collins J. Reduction in injury rates in nursing personnel through introduction of mechanical lifts in the workplace. Am J Ind Med. 2003;44:451-7. http://dx.doi.org/10.1002/ajim.10294.

24. Li J, Wolf L, Evanoff B. Use of mechanical patient lifts decreased musculoskeletal symptoms and injuries among health care workers. Inj Prev. 2004;10:212-6. http://dx.doi. org/10.1136/ip.2003.004978.

25. Wardell H. Reduction of injuries associated with patient handling. AAOHN J. 2007;55(10):407-12.

26. Alamgir H, Yu S, Fast C, Hennessy S, Kidd C, Yassi A. Efficiency of overhead ceiling lifts in reducing musculoskeletal injury among carers working in long-term care institutions. Inj. 2008;39(5):570-7. http://dx.doi.org/10.1016/j. injury.2007.11.420.

27. Brophy M, Achimore L, Moore-Dawson J. Reducing incidence of low-back injuries reduces costs. Am Ind Hyg Ass J. 2001;62:508-11. http://dx.doi.org/10.1202/00028894(2001)062<0508:RIOLBI>2.0.CO;2.

28. Chhokar R, Engst C, Miller A, Robinson D, Tate RB, Yassi A. The three-year economic benefits of a ceiling lift intervention aimed to reduce healthcare worker injuries. Applied Ergon. 2005;36:223-9. http://dx.doi.org/10.1016/j. apergo.2004.10.008.

29. Collins JW, Wolf L, Bell J, Evanoff B. An evaluation of a" best practices" musculoskeletal injury prevention program in nursing homes. Inj Prev 2004;10:206-11. http://dx.doi. org/10.1136/ip.2004.005595.

30. Engst C, Chhokar R, Miller A, Tate RB, Yassi A. Effectiveness of overhead lifting devices in reducing the risk of injury to care staff in extended care facilities. Ergon. 2005;48(2):187-99. http://dx.doi.org/10.1080/00140130412331290826.

31. Miller A, Engst C, Tate RB, Yassi A. Evaluation of the effectiveness of portable ceiling lifts in a new long-term care facility. Appl Ergon. 2006;37:377-85. http://dx.doi. org/10.1016/j.apergo.2005.05.012.

32. Park R, Bushnell T, Bailer A, Collins J, Stayner L. Impact of publicly sponsored interventions on musculoskeletal injury claims in nursing homes. Am J Ind Med. 2009;52:683-97. http://dx.doi.org/10.1002/ajim.20731.

33. Lipscomb HJ, Schoenfisch AL, Myers DJ, Pompeii LA, Dement JM. Evaluation of direct workers' compensation costs for musculoskeletal injuries surrounding a hospitalwide policy change to minimal manual lifting of patients and 
institution of mechanical lift equipment using longitudinal data and an internal injury control. Occup Environ Med. 2011 Dec 23. [Epub ahead of print] http://dx.doi.org/10.1136/ oemed-2011-100107.

34. Schoenfisch AL, Pompeii LA, Myers DJ, James T, Yeung Y, Fricklas E, et al. Objective measures of adoption of patient lift and transfer devices to reduce nursing staff injuries in the hospital setting. Am J of Industrial Medicine. 2011;54(12):935-45. http://dx.doi.org/10.1002/ajim.20998.

35. Lipscomb HJ, Schoenfisch AL, Myers DJ, Pompeii LA, Dement JM. Evaluation of direct workers' compensation costs for musculoskeletal injuries surrounding interventions to reduce patient lifting. Occupational and Environmental Medicine. 2012;69(5): 367-372. http://dx.doi.org/10.1136/ oemed-2011-100107.

36. Dement JM, Pompeii LA, Østbye T, Epling C, Lipscomb HJ, James T, et al. An integrated comprehensive occupational surveillance system for health care workers. Am J Ind Med. 2004;45(6):528-38. http://dx.doi.org/10.1002/ajim.20017.

37. Checkoway H, Pearce N, Crawford-Brown D. Cohort Studies. In: Checkoway, Pearce, Crawford-Brown, editors. Research Methods in Occupational Epidemiology. New York: Oxford University Press; 1989. p. 103-169.

38. Hilbe JM. Negative binomial regression. 2nd Edition. Cambridge, UK: Cambridge University Press; 2011.

39. Breslow NE, Day NE. Statistical Methods in Cancer Research. Volume II: The design and analysis of cohort studies. World Health Organization International Agency on Research for Cancer. New York: Oxford University Press; 1987.

40. Humphreys S. Obesity in patients and nurses increases the nurse's risk of injury lifting patients. Bariatric Nursing and Surgical Patient Care. 2007;2(1):3-6. http://dx.doi. org/10.1089/bar.2006.9998.

41. Lipscomb JA, Trinkoff AM, Brady B, Geiger-Brown J. Health care system changes and reported musculoskeletal disorders among registered nurses. Am J Pub Health. 2004;94(8):14316. http://dx.doi.org/10.2105/AJPH.94.8.1431.

42. Shindul-Rothschild J, Berry D, Long-Middleton E. Where have all the nurses gone? Final results of AJN's patient care survey. Am J Mat/Child Nurs. 1997;22(1):33-47.

43. de Castro AB. Barriers to reporting a workplace injury. Am J Nurs. 2003;103(8):112. http://dx.doi.org/10.1097/00000446200308000-00031.

44. O'Brien-Pallas L, Shamian J, Thomson D, Alksnis C, Koehoorn M, Kerr M, et al. Health Policy and Systems Work-Related Disability in Canadian Nurses. J Nurs Schol. 2004;36(4):352-7. http://dx.doi.org/10.1111/j.15475069.2004.04063.x.

45. Morse T, Dillon C, Warren N. Reporting of work-related musculoskeletal disorder (MSD) to workers' compensation. New Solutions. 2000;10(3):281-92.

46. Schoenfisch AL, Lipscomb HJ. Job characteristics and work organization factors associated with patient-handling injury among nursing personnel. Work. 2009;33(1):117-28.

47. Blessman JE. Differential Treatment of Occupational Disease v Occupational Injury by Workers' Compensation in Washington State. J Occup Med. 1991;33(2):121-6.

48. Lipscomb HJ, Schoenfisch AL, Myers DJ, Pompeii LA, James T, Dement JM, et al. (Duke University Medical Center, Durham, NC, USA). Final Report to the National Institute for Occupational Safety and Health: Effectiveness of Patient Lift Equipment. Washington, DC: National Institute for Occupational Safety and Health; 2010 Dec. RO1 OH008375.

49. Shannon HS, Robson LS, Sale JEM. Creating safer and healthier workplaces: role of organizational factors and job characteristics. Am J Ind Med. 2001;2001(40):319-34. http:// dx.doi.org/10.1002/ajim.1106.

Received for publication: 27 October 2011 